\title{
Synthesis, Characterization and Antimicrobial Activity of 2-[1-(2,4- Dihydroxyphenyl) Ethylene]Hydrazine Carboxamide and its Zn(II) Metal Complex
}

\author{
Ratnamala P. Sonawane \\ The Institute of Science, Mumbai-32. India \\ ratnasonawane@yahoo.in
}

Keywords: Semicarbazone, metal complex, antimicrobial, diffusion method, IR spectroscopy.

\begin{abstract}
The synthesis of 2-[1-(2,4-dihydroxyphenyl)ethylene]hydrazinecarboxamide and its $\mathrm{Zn}$ (II) metal complex was achieved. 2, 4 dihydroxy acetophenone is synthesized by resorcinol with glacial acetic acid. This further treated with semicarbazide hydrochloride to form its semicarbazone. $\mathrm{Zn}$ (II) metal complex was prepared by dissolving equimolar quantities of metal salt and Schiff base ligand in ethanol. All the target compounds were characterized by M.P, TLC and UV-visible and IR spectral data. Antimicrobial activities of these synthesized compounds were studied in sterile saline by Agar well diffusion method against M. luteus, B. subtilis, S. aureus, E. coli, P. aeruginosa bacteria. All the synthesized compounds have shown good to moderate antimicrobial activity.
\end{abstract}

\section{Introduction}

Hydroxy acetophenones and its derivatives were used as starting material for the synthesis of chalcones [1], flavones [2] and Schiff bases [3, 4] etc. Hydroxy acetophenone semicarbazone have wide spectrum of biological activities. Schiff bases and their co-ordination compounds have great importance as they are useful in biochemical [5], anticancer [6], anti-inflammatory [7] and antipyretic [8]. A Schiff base of hydroxyl acetophenone and its complexes has variety of applications in biological, clinical, analytical and pharmaceutical area [9, 10]. Metal ions are the factors in the structural organization of biochemical molecules and the functional processes operating in the genetic and metabolic systems [11]. Transition metal ions and their complexes are the essential components found in all living organisms [12]. The interaction of transition metal ions with biologically active ligands is a subject of interest. Studying the biological activities of metal complexes is interesting. Thus the aim of the present work is to synthesize some new hydroxyacetophenones, its derivatives, $\mathrm{Zn}$ metal complex and to study their antimicrobial activities [13-18]. Their structures were elucidated on the basis of MP, TLC, elemental analysis, UV-visible and IR spectral data. All the synthesized compounds have been screened for their biological activity by Agar well diffusion method.

\section{Materials and Methods}

The chemicals used in the present work were dry resorcinol, glacial acetic acid, powdered Zinc chloride, semicarbazide hydrochloride, anhydrous sodium acetate, ethanol etc. all these chemicals were purchased from Zen Scientific, Mumbai and were of AR grade. All these chemicals were used for synthesis.

Test Microorganism: The microorganism used in the present study were M. luteus, B. subtilis, S. aureus, E. coli, $P$. aeruginosa.. Microorganisms were maintained at $4^{\circ} \mathrm{C}$ on nutrient agar slants.

The reagent 2-[1-(2,4-dihydroxyphenyl)ethylene]hydrazinecarboxamide and its $\mathrm{Zn}$ (II) metal complex was prepared as reported in the literature. The structure of the Schiff base is confirmed by using physical methods like melting point, TLC, elemental analysis, UV-visible and IR spectra. The newly synthesized $\mathrm{Zn}$ complex was characterized on the basis of microanalysis data, elemental analysis, UV-visible and IR. 


\section{Synthesis of 2,4-dihydroxyacetophenone}

Briefly, the synthesis was carried out by dissolving freshly fused and powdered zinc chloride ( 0.24 mole) in $32 \mathrm{ml}$ of glacial acetic acid by heating on sand bath. Dry resorcinol ( 0.2 mole) was added with stirring at $140^{\circ} \mathrm{C}$. The solution was heated until it just begins to boil and kept for 20 minutes at $150^{\circ} \mathrm{C}$. Dilute $\mathrm{HCl}(1: 1)$ was added to the mixture and the solution was cooled to $5^{0} \mathrm{C}$. The separated product was filtered and washed with dilute $\mathrm{HCl}$. The product was recrystallized from hot water. The reaction Scheme is given in Fig. 1.

\section{Reaction Scheme:}

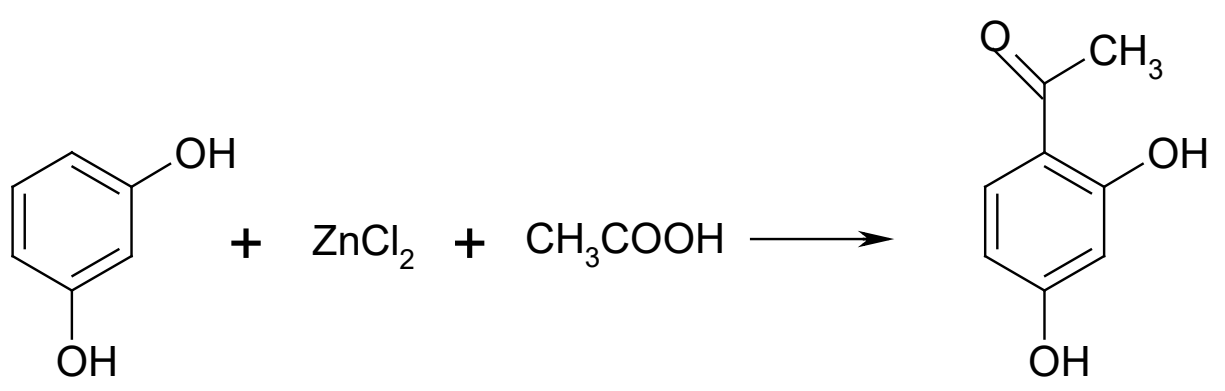

Figure 1. Reaction scheme for the synthesis of 2,4-dihydroxyacetophenone

\section{Synthesis of Semicarbazone Derivative:}

1 gram of powdered semicarbazide hydrochloride was added 0.9 gram of anhydrous sodium acetate to $5 \mathrm{ml}$ of water and was warmed gently until a clear solution is appeared. A solution of $1 \mathrm{gm}$ of 2, 4 dihydroxyacetophenone in $5 \mathrm{ml}$ of ethanol was added. The mixture was warmed gently in a water bath for 15 mins. The semicarbazone rapidly crystallizes. Finally, cool filter off the 2,4 dihydroxyacetophenone Semicarbazone, washed thoroughly with water and was drained. Recrystallised from ethanol. Melting point is $201^{\circ} \mathrm{C}$. The reaction Scheme is given in Fig. 2.

\section{Reaction Scheme:}<smiles>CC(=O)c1ccc(O)cc1O</smiles><smiles>NNC(N)=O</smiles>

Semicarbazide Hydrochloride<smiles></smiles><smiles>C/C(=N\NC(N)=O)c1ccc(O)cc1O</smiles>

2-[1-(2,4-dihydroxyphenyl)ethylidene]hydrazinecarboxamide

Figure 2. Reaction scheme for the synthesis of 2-[1-(2,4dihydroxyphenyl)ethylene]hydrazinecarboxamide 


\section{Synthesis of Zn(II) Compex:}

The ligand (Schiff base) $(0.1 \mathrm{~mm})$ was taken in hot ethanol $(40 \mathrm{~mL})$ and treated with a hot ethanolic solution of $\mathrm{ZnCl}_{2}(0.1 \mathrm{~mm})$ the light yellow transparent solution of ligand changed to colourless after mixing the solution. This reaction mixture was refluxed for $8 \mathrm{hrs}$ and mixture of solution was cooled, left to stand overnight, filtered by under suction. Crystalline solid was separated out and recrystallized from ethanol. The yield $70 \%$ and melting point $345^{\circ} \mathrm{C}$. The reaction Scheme is given in Fig. 3.

\section{Reaction:}<smiles>C/C(=N\NC(N)=O)c1ccc(O)cc1O</smiles><smiles>Cc1nn2c3ccc(O)cc3on1C(=O)NC2=O</smiles>

Figure 3. Reaction scheme for the synthesis of $\mathrm{Zn}$ Complex of 2-[1-(2,4dihydroxyphenyl)ethylene]hydrazinecarboxamide

Spectral Analysis: The structure of all synthesized compounds was confirmed by Elemental analysis, Uv-visible and IR Spectroscopic technique. The absorbance measurement was carried out on Shimarzu Uv-visible 2100 spectrophotometer with $1 \mathrm{~cm}$ quartz cell. The IR spectra were recorded on Shimadzu FT-IR-8400 instrument using KBr pellet method.

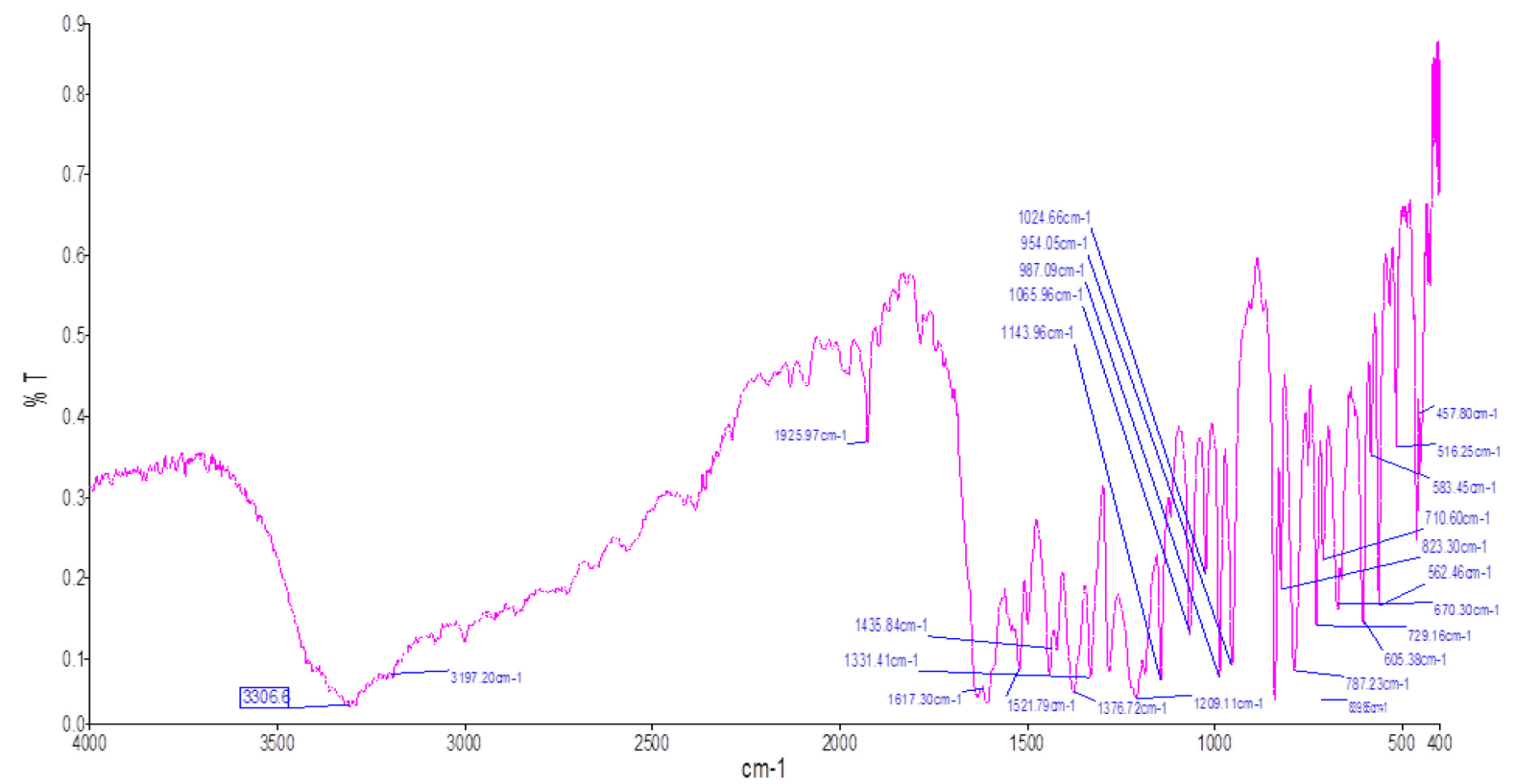

Figure 4. IR for 2,4- dihydroxyacetophenone 


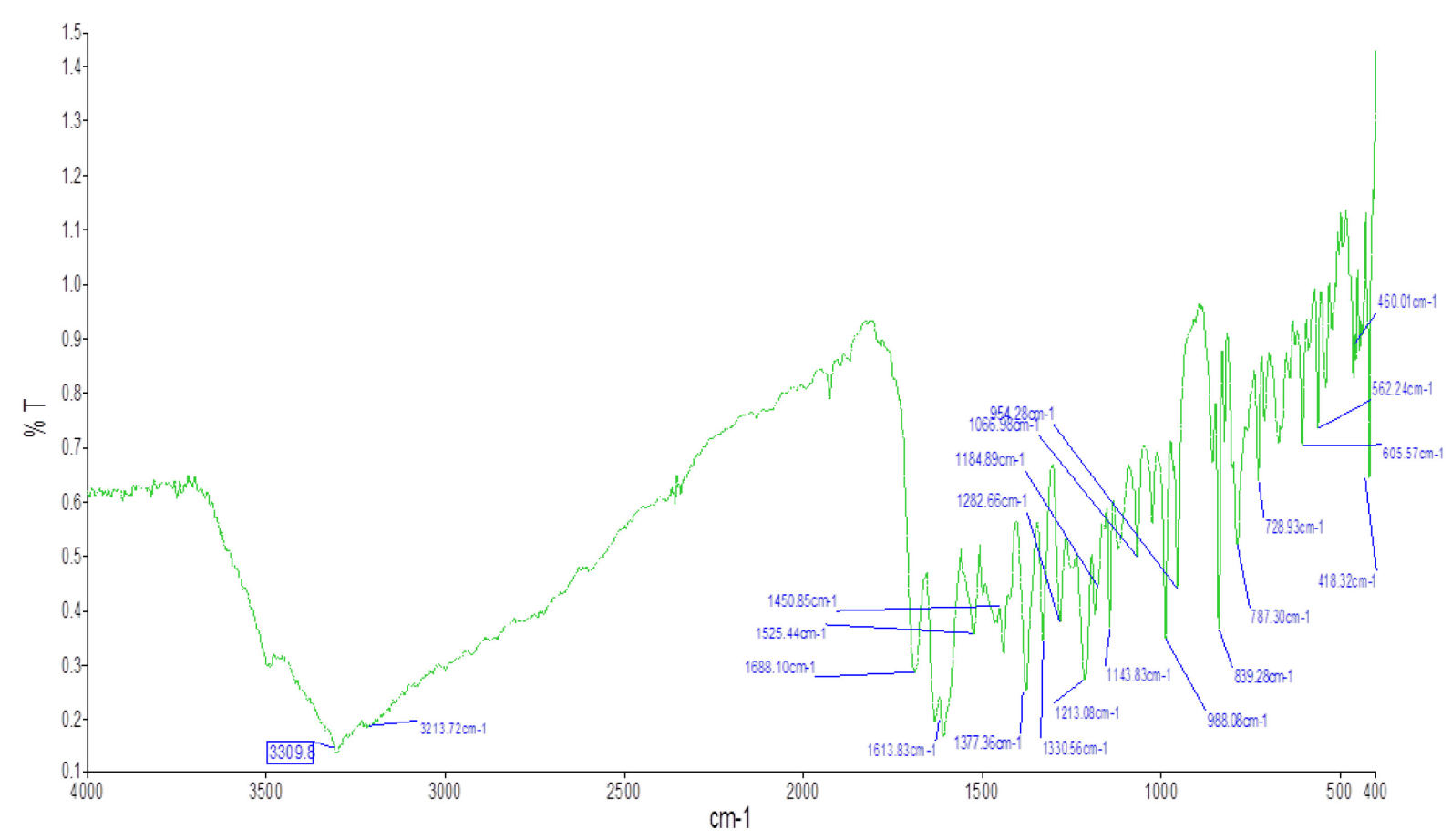

Figure 5. IR for 2,4- dihydroxyacetophenone Semicarbazone

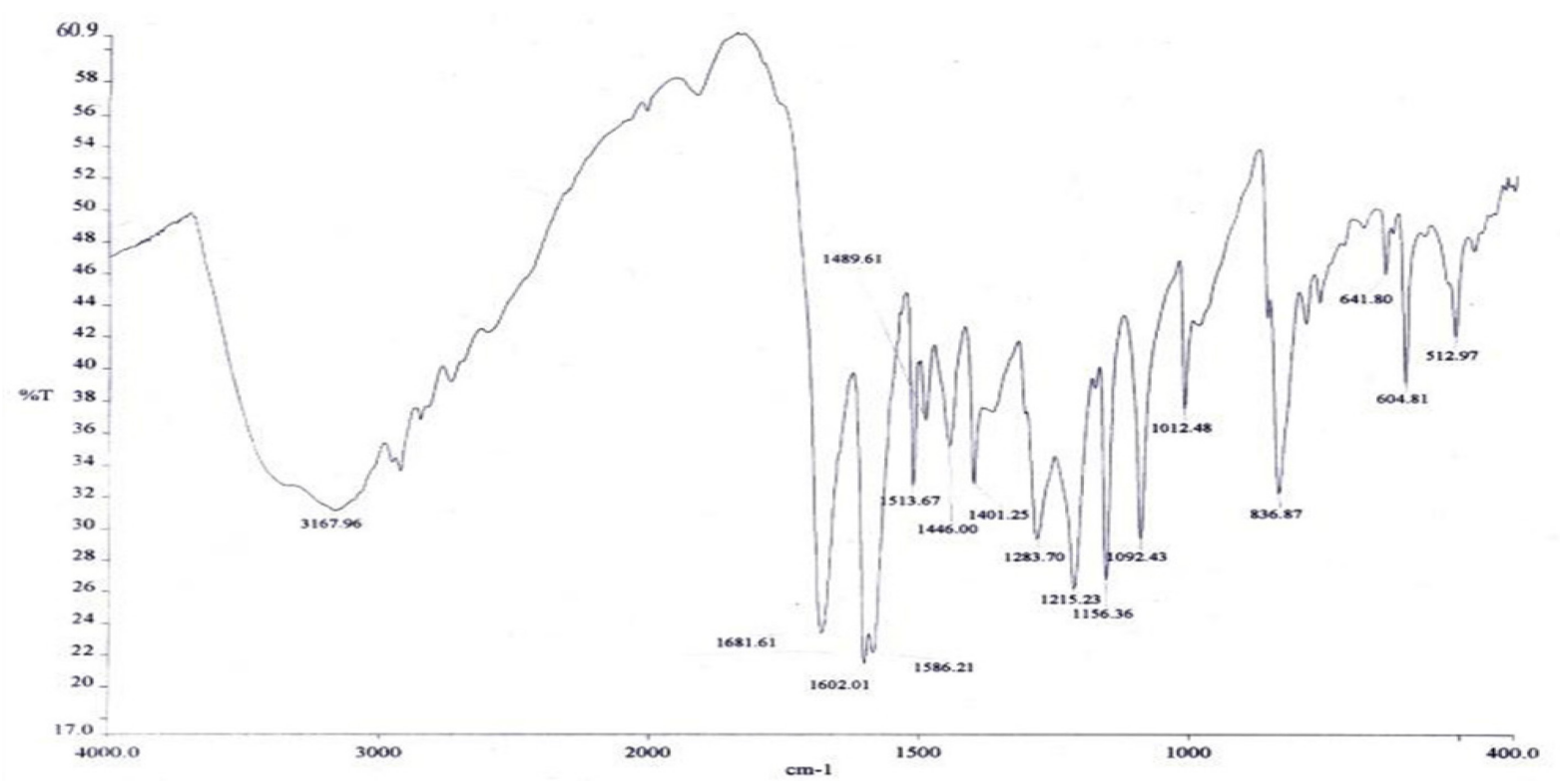

Figure 6. IR for Zn Complex of 2-[1-(2,4-dihydroxyphenyl)ethylene]hydrazinecarboxamide

Antimicrobial studies: For antimicrobial activity the suspension of synthesized compounds and $\mathrm{Zn}$ (II) metal complex was made with sterile saline. In the present work the antimicrobial activities of the synthesized compounds have been screened against M. luteus, B. subtilis, S. aureus, E. coli, P. aeruginosa.

Preparation of test compounds: The solutions were prepared at a concentration of $1 \mathrm{mg} / \mu \mathrm{l}$ for all the compounds.

Preparation of Plates and Microbiological assay: The antimicrobial evaluation was done by Agar well diffusion method [19, 20] using Mueller Hinton Agar no.2 as the nutrient medium. The bacterial strains were activated by inoculating loop full of strain in $20 \mathrm{~cm} 3$ of nutrient agar and the same was incubated for $36 \mathrm{hrs}$. in an incubator at $37^{\circ} \mathrm{C} \cdot 0.1 \mathrm{~cm} 3$ of the activated strain was inoculated in Mueller Hinton agar. Mueller Hinton agar was kept at $45^{\circ} \mathrm{C}$ and then poured in the 
petri dishes and allowed to solidify. After solidification of the media, $0.85 \mathrm{~cm}$ ditch was made in the plates using a sterile cork borer and these were completely filled with the test solution. The plates were incubated for $36 \mathrm{hrs}$. at $37^{\circ} \mathrm{C}$. The mean value obtained for the three wells was used to calculate the zone of growth inhibition of each sample. The inhibition zone formed by these compounds against the particular test bacterial strain determined the antibacterial activities of these synthesized compounds.

\section{Results}

2,4- dihydroxyacetophenone, its semicarbazone derivative and its $\mathrm{Zn}(\mathrm{II})$ metal complex are synthesized. The synthesized compounds were purified by recrystallization method. The purity of the compounds was checked by TLC using appropriate solvent systems. The physical and analytical parameters were checked. (Table1) The structure of all the synthesized compounds was confirmed by UV-visible and IR spectroscopic technique.

\section{Spectral Data}

2,4-dihydroxyacetophenone: IR( $\left.\mathrm{cm}^{-1}, \mathrm{KBr}\right) 3307$ (aro, O-H str), 3197.20(aro, C-H str), 1521.79(aro, $\mathrm{C}=\mathrm{C}$ str), 1925.97(OH para sub), $1800(\mathrm{OH}$ ortho sub), $1617.30 \mathrm{C}=\mathrm{O}$ conj), 1143.96(aro, C-O str), 823.30(para sub), 729.16(ortho sub). (Table 2)

2,4-dihydroxyacetophenone semicarbazone: : IR( $\mathrm{cm}^{-1}, \mathrm{KBr}$ ) 3309(aro, O-H str), 3212.72(aro, C-H str), 1525.44(aro, $\mathrm{C}=\mathrm{C}$ str), 1213.08(C-N str), 1143.83(aro, C-O str), 1688.10( $\mathrm{C}=\mathrm{O}$ conj), 1143.96(aro, C-O str), 839.28(para sub), 728.93(ortho sub). (Table 2)

Zn Complex of 2-[1-(2,4-dihydroxyphenyl)ethylene]hydrazinecarboxamide: $\mathrm{IR}\left(\mathrm{cm}^{-1}, \mathrm{KBr}\right)$ 3167.96(aro, O-H str), 1586.21(aro, C=C str), 1283.70(C-N str), 1156.36(aro, C-O str), 1681.61 (sec/tert amide), 836.67(para sub), 512.97 (M-O str) (Table 2)

\section{Antimicrobial Activity}

Microbial assay was carried out by agar well diffusion method. The bacterial strains were activated by inoculating loop full of strain in $20 \mathrm{~cm} 3$ of nutrient agar and the same was incubated for $36 \mathrm{hrs}$. in an incubator at $37^{\circ} \mathrm{C}$. The zone of inhibition in different bacterial strains i.e. M. luteus, B. subtilis, $S$. aureus, E. coli, P. aeruginosa against synthesized compounds shown in Table 3. Among the various bacterial strains maximum zone of inhibition was recorded in $S$. aureus and minimum zone of inhibition was observed in M. luteus and P. aeruginosa.

Table 1. Physical and analytical data

\begin{tabular}{|l|l|l|l|l|l|l|}
\hline Compound & Color & M.P. $\left({ }^{\mathbf{0}} \mathbf{C}\right)$ & $\boldsymbol{\lambda} \mathbf{m a x}$ in $\mathbf{n m}$ & \multicolumn{4}{|c|}{ Elememtal analysis\% } \\
\hline & & & & C & H & N \\
\hline I & Off white & 143 & 217 & 63.15 & 5.30 & -- \\
\hline II & Pale yellow & 201 & 342 & 59.01 & 3.90 & 5.45 \\
\hline III & Yellow & 345 & 385 & 58.40 & 3.43 & 6.62 \\
\hline & & & & & & \\
\hline
\end{tabular}


Table 2. Spectral Data

\begin{tabular}{|l|l|l|l|}
\hline Group \& vibration & \multicolumn{1}{|c|}{$\begin{array}{c}\text { Frequency's } \\
\text { in } \mathbf{~ c m}^{-1}\end{array}$} & \multicolumn{1}{|c|}{$\begin{array}{c}\text { Frequency's } \\
\text { In } \mathbf{~ c m}^{-1} \\
\text { II }\end{array}$} & \multicolumn{1}{|c|}{ III } \\
\hline Aro, O-H Streching vibration & 3307 & 3309 & 3167.96 \\
\hline Aro, C-H Streching vibration & 3197.20 & 3212.72 & ----- \\
\hline Aro, C=C Streching vibration & 1521.79 & 1525.44 & 1586.21 \\
\hline OH para subsituted & 1925.97 & 1922 & ----- \\
\hline OH ortho subsituted & 1800 & 1805 & ----- \\
\hline C=O conjugation & 1617.30 & 1688.10 & ----- \\
\hline Aro, C-O Streching vibration & 1143.96 & 1143.83 & 1156.36 \\
\hline Para substitution & 823.30 & 839.28 & 836.67 \\
\hline Ortho substitution & 729.16 & 728.93 & 727 \\
\hline Aro, C-N streching & ---- & 1213.08 & 1283.70 \\
\hline Tertiary amide & ---- & --- & 1681.61 \\
\hline M-O streching & ---- & --- & 512.97 \\
\hline
\end{tabular}

Table 3. Antibacterial activity

\begin{tabular}{|c|c|c|c|c|c|c|}
\hline \multirow{2}{*}{ Entry } & \multirow{2}{*}{ Substt } & \multicolumn{5}{|c|}{ Zone of Inhibition in mm } \\
\cline { 3 - 7 } & & \multicolumn{4}{|c|}{ Gram positive Bacteria } & Gram negative Bacteria \\
\cline { 3 - 7 } & & M. luteus & B. subtilis & S. aureus & E. coli & P. aeruginosa \\
\hline 1. & I & 12 & 15 & 19 & 13 & 12 \\
\hline 2. & II & 14 & 16 & 21 & 15 & 13 \\
\hline 3. & III & 15 & 18 & 25 & 23 & 15 \\
\hline 4. & Ampicillin & 17 & 19 & 26 & 24 & 17 \\
\hline
\end{tabular}

I 2,4- dihydroxyacetophenone

II 2,4- dihydroxyacetophenone Semicarbazone

III Zn Complex of 2-[1-(2,4-dihydroxyphenyl)ethylene]hydrazinecarboxamide

\section{Discussion}

The results indicate that inhibition depends on strain and structure.in compound $\mathrm{I}$ due to presence of $\mathrm{C}=\mathrm{O}$ only it shows less inhibition. But in compound II due to presence of $\mathrm{C}=\mathrm{N}$ imine group inhibition increases comparation to compound I. Also a broad band at 3500-3400 is attributed to intermolecular hydrogen bonded $-\mathrm{OH}$ group, at 1600-1700 $\mathrm{C}=\mathrm{O}$ (amide) strong absorption, Medium sharp absorption band around 3200-3100 N-H stretching vibration, Strong absorption band 1600-1675 due to tertiary amide. Aromatic C-H band at 3000-2900. Physicochemical studies have been used in the elucidation of the geometry of the metal complexes with the purpose of throwing light on the structural aspects of newly synthesized Schiff base complexes. The newly synthesized ligand and its $\mathrm{Zn}$ (II) metal complex were characterized by elemental analysis, UV-visible, IR, TLC and repeated MPs determination studies. The susceptibility of the contain strains of bacteria towards the synthesized compounds was determined by measuring the size of inhibition diameter. $\mathrm{Zn}$ (II) complexes were highly effective against $M$. luteus, B. subtilis, S. aureus, E. coli, P. aeruginosa than their parent compound. It was also observed that antibacterial activity of these complexes for removing bacteria was fairly good.

\section{Conclusions}

2,4- dihydroxy acetophenone, its semicarbazone derivative and $\mathrm{Zn}$ (II) metal complex were synthesized. The structures of synthesized compound were supported by IR spectroscopic technique. The antibacterial screening of these compounds shows that inhibition depends on strain 
and structure. Presently, there is an emergence of multiple drug resistance to human pathogenic organism. So there is an urgent need to develop alternative antimicrobial drugs for the treatment of infectious diseases. The clinical isolated bacteria in this study were M. luteus, B. subtilis, S. aureus, $E$. coli, $P$. aeruginosa. These isolates of bacteria caused high percentage of drug resistance. The antibacterial study showed that complexes are found to be more active against M. luteus, B. subtilis, $S$. aureus, E. coli, $P$. aeruginosa. Compared to standard antibacterial compound the complexes show moderate activity against the selected strains of microorganisms.

\section{Conflict of Interest}

The author declares that there is no conflict of interest.

\section{References}

[1] V.E. Kuzmin et al., Investigation of anticancer activity of macrocyclic Schiff bases by means of 4D-QSAR based on simplex representation of molecular structure, SAR and QSAR Environ. Res. 16(3) (2005) 219-230.

[2] W. Sawodny, M. Riederer, E. Urban, Preparation and thermal stability of polymeric metal chelates with Schiff bases, Inorg. Chim. Acta. 29 (1978) 63-68.

[3] S. Oshima et al., Structural control of Schiff base ligands for Selective extraction of copper(II), Anal. Sci. 18(12) (2002) 1351-1355.

[4] V.S. Agarwala et al., Synthetic lubricating oil greases containing metal chelates of Schiff bases, US patent 5,147,567, (1992).

[5] G.S. Trivedi, N.C. Desai, Indian Journal of Chemistry. B. 31 (1992) 366.

[6] P. Singh, R. Goel, B.P. Singh, 8-acetyl-7-hydroxy-4-methyl coumarin as a gravimetric reagent for $\mathrm{Cu}^{+2}$ and $\mathrm{Fe}^{+3}$, J. Ind. Chem. Soc. 52(10) (1975) 958-959.

[7] A.M. Mohindru, J.M. Fisher, M. Rabinovitz, Bathocuproine sulphonate: a tissue culturecompatible indicator of copper-mediated toxicity, Nature. 303(5912) (1983) 64.

[8] J. Kleinberg, W.J. Argersinger, E. Grisworld, Inorganic chemistry, Chapter 6, D.C. Heath and Company: Boston, MA, 1960.

[9] G.L. Miessler, D.A. Tarr, Inorganic chemistry, Second Edition, Prentice-Hall: Upper Saddle River, NJ, 1999.

[10] J.C. Sheehan, V.J. Grenda, The N-(2-Hydroxyarylidene) protecting group in peptide synthesis, J. Amer. Chem. Soc. 84(12) (1962) 2417-2420.

[11] J.P. Glusker et al., Metal ions in biological systems, Rigaku J. 16(2) (1999) 8-16.

[12] P.M. Sabale et al., Metal complexes: current trends and future potential, J. Pharma. Chem. Biol. Sci. 2 (3)(2012) 251-265.

[13] S. Kumar, D.N. Dhar, P.N. Saxena, Applications of metal complexes of Schiff bases - A review, J. Sci. Ind. Res. 68 (2009) 181-187.

[14] K. Singh, M.S. Barva, P. Tyagi, Synthesis, characterization and biological studies of Co(II), $\mathrm{Ni}(\mathrm{II}), \mathrm{Cu}(\mathrm{II})$ and $\mathrm{Zn}(\mathrm{II})$ complexes with bidentate Schiff bases derived by heterocyclic ketones, Eur. J. Med. Chem. 41 (2006) 147-153.

[15] M. Raman et al., Synthesis, characterization and electrochemical behaviour of Cu(II), Co(II), $\mathrm{Ni}(\mathrm{II})$ and $\mathrm{Zn}(\mathrm{II})$ complexes derived from acetylacetone and $\mathrm{p}$-anisidine and their antimicrobial activity, Indian Acad. Sci. Chem. Sci. 115 (2003) 161-167. 
[16] J.M. Desai, K.K. Desai, Synthesis and antibacterial activity of oximes, semicarbazones and thiosemicarbazones, Asian J. Chem. 11 (1999) 1071-1073.

[17] A. Cukurovali et al., Schiff base ligands containing cyclobutane and their metal complexes with $\mathrm{Co}(\mathrm{II}), \mathrm{Cu}(\mathrm{II}), \mathrm{Ni}(\mathrm{II})$ and $\mathrm{Zn}(\mathrm{II})$ complexes of two novel Schiff base ligands and their antimicrobial activity, Trans. Met. Chem. 27(2) (2002) 171-176.

[18] X. Song et al., Synthesis and biological activity of Schiff bases of 2-amino-5-(4-pyridyl)1,3,4-thiodiazol, Chinese Journal of Applied Chemistry. 22 (2005) 334-336.

[19] C. Perez, M. Pau, P. Bazerque, An antibiotic assay by agar diffusion method, Acta Biol. Med. Exp. 1591 (1990) 113-115.

[20] S. Baluja, S. Chanda, Pyrazoline derivatives: Synthesis and antimicrobial studies, World. Res. J. Biochem. 1(1) (2012) 6-10. 